\title{
БИФУНКЦИОНАЛЬНОСТЬ КАК ОТРАЖЕНИЕ ДИНАМИКИ РАЗВИТИЯ ЯЗЫКОВОЙ СИСТЕМЫ (НА МАТЕРИАЛЕ СОВРЕМЕННОГО НЕМЕЦКОГО ЯЗЫКА)
}

\author{
С. В. Постникова, В. Н. Егорова, А. А. Ефимов \\ Национальный исследовательский Нижегородский государственный университет \\ имени Н. И. Лобачевского

\section{BIFUNCTIONALITY AS A REFLECTION OF THE DYNAMICS OF THE DEVELOPMENT OF THE LANGUAGE SYSTEM (ON THE DATA OF MODERN GERMAN)}

\author{
S. V. Postnikova, V. N. Egorova, A. A. Efimov \\ Lobachevsky National Research Nizhny Novgorod State University
}

\begin{abstract}
Аннотация: статья посвящена анализу особенностей семантико-функциональной вариабельности конституентов функиионально-семантических полей адъективной лексики (типа tief) и сравнения сходства, включающего отсубстантивные деривационные модели на -ig (unsinnig), -en (gewissermaßen), -lich (unglaublich), -isch (schweinisch) и т. n., субстантивные дериваты с полупрефиксами еrz-, super-, ur-, extra-, hyper-, ober-, ultra- u m. n. (muna Erzheuchler, Superschlitten, Hyperdummheit, Ultraidee, Urwahrheit, ExtraSauberkeit usw.), а также субстантивные и адъективные композиты (mипа leichenblaß и Bombenleistung). Данные единицы проявляют тенденцию к семантико-функииональному сдвигу в сторону качественнооценочной характеризации предмета или интенсификации признака под влиянием социально обусловленных и лингвистических факторов. Исследование было проведено на основе коммуникативно-деятельностного подхода с использованием следующих методов: компонентного анализа, трансформационного преобразования и описания. В ходе анализа были выявлены основные закономерности формирования бифункичональности у анализируемых единии, которая характерна для периферийных конституентов функиионально-семантических полей сравнения, качественности признака, оценки, интенсивности и нередко является результатом их использования в речевом акте, в том числе при нарушении парадигматически обусловленной лексико-грамматической сочетаемости единии, используемых при формировании высказывания. В результате создаются предпосылки для формирования так называемых «промежуточных зон» между микрополями и соположенными функционально-семантическими полями сравнения и интенсивности, а также качественности признака и оценки. Данный процесс свидетельствует о континуальности соответствующих структурных образований и является частным случаем, подтверждающим не только «размытость» границ исследуемых функционально-семантических полей и их развитие, но и динамику развития языковой системы в изелом.
\end{abstract}

Ключевые слова: функционально-семантическое поле, микрополе, «промежуточные зоны», континуальность системы, сравнение, качественно-оценочная характеристика, интенсивность.

\begin{abstract}
: the article is concerned with analyzing the semantic and functional variability of constituents of functional-semantic fields of adjectival vocabulary and comparison of substantive derivational models -ig, -en, -lich, -isch, etc., the noun derivatives with prefixoids erz-, super-, ur-, extra-, hyper-, ober-, ultra -, etc., as well as substantive and adjectival complex words. It aims at defining the features of this variability depending on communicative intentions of the speakers in the process of the speech act. The research bases on using the method of communicative and activity approach, which helps to determine the peripheral segments, capable of "migrating"
\end{abstract}

(C) Постникова С. В., Егорова В. Н., Ефимов А. А., 2021 
from one field to another one. The above-listed units show a tendency to semantic and functional shift towards qualitative and evaluative characterization of the subject or the intensification of the marker under the influence of socially determined and linguistic factors. As a result, some of above-mentioned constituents are open to perform functions that are not typical for them, depending on the contextual environment and, first of all, on the situation of communication. This creates the possibility for the formation of "intermediate zones" between the microfields and the adjacent functional-semantic fields of comparison and intensity, which reflect the continuity of the corresponding structural formations and the language system as a whole, so are a special case of bifunctionality, which demonstrates the dynamic development of functional-semantic fields. The research might be usefull for the further investigation of similar peripheral segments of other functional-semantic fields.

Key words: functional-semantic field, microfield, "intermediate zones", continuality of the system, comparison, qualitative-evaluative characteristic, intensity.

\section{Введение}

Речемыслительная деятельность как активный процесс восприятия и категоризации объективной действительности, субъективно-оценочной характеристики ее качественных сторон и вербализации познанного необходимо предусматривает обмен информацией о полученном опыте в социально-общественном дискурсивном пространстве. С этим связана поистине неисчерпаемая возможность использования языковых средств, востребованная главной коммуникативной интенцией общего дискурса, в том числе при создании косвенных речевых актов. Речь идет, в частности, о семантико-функциональной гибкости и вариабельности языковых единиц, особенно в речетворческом процессе формирования высказывания.

Систематизация таких языковых средств, как функционально-семантические поля (ФСП), с присущей им динамикой внутриструктурных отношений между конституентами предполагает открытость границ между микрополями и соположенными полями и соответственно наличие так называемых «промежуточных зон», обеспечивающих континуальность языковой системы в целом. В этом плане необходимость исследования их природы очевидна и не утрачивает актуальности в настоящее время. Как отмечал Л. В. Щерба, «...надо помнить, что ясны лишь крайние случаи. Промежуточные же в самом первоисточнике - в сознании говорящих - оказываются колеблющимися, неопределенными. Однако это-то неясное и колеблющееся и должно больше всего привлекать внимание лингвистов» $[1$, с. $35-36]$.

Как представляется, такие «промежуточные зоны» образуют единицы, семантическая бифункциональность которых либо закреплена за ними в системе языка как ЛСВ, либо приобретается в дискурсе при формировании косвенного речевого акта.

В данной статье предпринимается попытка выявить и охарактеризовать особенности становления семантической бифункциональности единиц, образующих в периферийных сегментах функционально-семантических полей качественной признаковости и сравнения (сходства) «промежуточные зоны».

\section{Исследовательская часть}

В качестве иллюстративного материала послужили примеры из немецкой художественной прозы двадцатого столетия и современной публицистики, рассмотрение которых предпринимается с помощью методов: компонентного анализа, трансформационного преобразования, описания.

\section{Основные закономерности формирования бифункииональности как фактор создания «промежуточных зон»}

Как показывает анализ, динамика развития обоих полей прослеживается в двух направлениях: в перестройке конституентов названных сегментов ФСП на выполнение семантической функции качественной/ качественно-оценочной характеризации предмета, явления или в ориентации на выполнение интенсифицирующей функции, хотя не исключается и взаимообусловленность данных функций.

Потенциальная предрасположенность сравнения сходства, ассоциативного по своей природе, к выполнению оценочной функции при образной характеристике сравниваемого объекта нередко является стимулом для их использования в качестве интенсификатора. Дискурсивно обусловленная реализация данной функции характеризуется не только семантической неконгруэнтностью сравниваемых, но прежде всего использованием в роли эталона сравнения такого объекта, который конвенционально воспринимается коммуникантами в речевом акте как типичный носитель признака в наиболее ярком его проявлении. При этом семантика сравнительных отношений практически нейтрализуется за счет доминантности интенсифицирующей функции, а сама синтаксическая структура выступает как бифункциональная единица в промежуточной зоне между функционально-семантическими полями сравнения и интенсификации. Например: Selbst seine Stimme klingt wie Asche / Caм его голос звучал глухо (дословно как пепел) [2, S. 18], где помимо явного сравнения etwas $V$ wie etwas наблюдается процесс деинтенсификации высказывания, т. е. звучать как пепел может обозначать звучать бесиветно, глухо, без выражения или эмоций. 
Наиболее явно такая тенденция проявляется в компаративных фразеологических единицах (КФЕ), представляющих особый интерес для изучения, в том числе на основании того, что данный класс языковых единиц является неограниченно открытым и постоянно пополняется. КФЕ экспрессивны по своей сути, и их компоненты, как правило, утрачивают свои самостоятельные значения, сема сравнения также отходит на второй план, так, например, КФЕ dumm wie Bohnenstroh - глуn как пробка (дословно глуn как бобовая солома) имеет толкование в словаре umgangssprachlich abwertend: sehr dumm [sein]-paзz., сниж.: очень глупым [быть] [3], причем в дискурсе сравнительная характеризация КФЕ модели $\mathrm{A}+\mathrm{wie}+\mathrm{S}$ уступает место интенсифицирующей семе, ср.:

Er ist dumm wie Bohnenstroh. Sein Charakter ist unfassbar loyal, aufopfernd und herzlich, aber eben richtig doof / Он глуn, как пробка. По характеру он невероятно верный, жертвенен и сердечен, но прямо-таки глуn [4]. Таким образом, КФЕ приобретают «целостное интенсифицирующее значение» [5, c. 110].

Нередко высокая частотность употребления таких единиц в функции интенсификаторов приобретает системообразующий характер и фиксируется словарями, например: verschwiegen wie ein Grab = ganz verschwiegen [6, S. 167].

Показательна в этом плане тенденция к приобретению семантической бифункциональности некоторых словообразовательных моделей - отсубстантивных дериватов на -ig, -en, -lich, -isch и др. и детерминативных субстантивных и адъективных словосложений. Данная тенденция заключается в частичной или полной нейтрализации изначально присущей данным единицам семантики сравнительных отношений, а для словообразовательных моделей соответственно в утрате синтаксичности внутрикомпонентных отношений, что напрямую связано с семантико-функциональным сдвигом в сторону выражения качественно-оценочной характеризации предмета, явления, а также интенсивности проявления признака.

Подобное положение дел наблюдается и в субстантивных дериватах с полупрефиксами erz-, super-, ur-, extra-, hyper-, ober-, ultra- и др., которые и привносят интенсифицирующее значение. Так, например, в предложении Nun konnte er im Regierungsauftrag allen Erzhalunken fliegend ein Schnippchen schlagen, eren kriminelles Ziel in der Regel mindestens die Weltherrschaft war / Tеперь в правительственном приказе он мог нанести удар по всем величайшим подлецуам, преступной целью которых, как правило, было как минимум мировое господство [4]. Дериват der Erzhalunke / величайший подлеи выполняет не просто качественно-оценочную характеристику, которая, кстати, полностью не нейтрализуется, но, отвечая иллокуции высказывания, используется в первую очередь для выражения интенсивности, усиления негативной оценочной характеристики.

Процесс подобной семантико-функциональной переориентации данных словообразовательных моделей обусловлен возрастающей потребностью социума использовать их именно в данном амплуа для достижения в речевом акте необходимого перлокутивного эффекта.

Заметим также, что вхождение в систему адъективной лексики выделенных выше моделей отсубстантивных дериватов предопределено не столько выполняемыми или вторичными функциями указания на род, число, падеж определяемого, сколько аттракцией ядерной части ФСП, которую образуют истинно качественные прилагательные (цветообозначения, параметрические и т. п.). В то же время процесс их лексикализации занимает исторически длительный период и связан с высокой частотностью использования данных единиц в речевом акте в новой, отмеченной выше функции. При этом в основе подобной семантико-функциональной перестройки находится социально обусловленное расширение лексико-семантической сочетаемости дериватов, в ходе которого в обобщенном предметном значении мотивирующей субстантивной основы выделяется и постепенно закрепляется имплицитная сема качественного признака, который начинает конвенционально восприниматься как релевантный для предмета, в то время как семантика «живой» синтаксической связи между компонентами синтагмы или композита частично или полностью нейтрализуется (ср.: goldener Ring (предметно-относительное значение: der Ring aus Gold) и goldenes Herz (качественно-оценочное значение с оттенком интенсификации herrliches, schönes Herz); das diplomatische Korps (предметно-относительное значение) и: diplomatisch (качественно-оценочное значение = gewandt, klugberechnend: diplomatisch Lächeln, sein, vorgehen, sich benehmen).

Следует также упомянуть, что к переориентации на выполнение интенсифицирующей функции предрасположены и корневые качественные прилагательные, что предопределено открытостью их плана содержания к привнесению эмоционально-оценочных коннотаций. Соответственно такие прилагательные потенциально предрасположены к выполнению не только функцию качественной/качественно-оценочной характеристики [7, с. 399], но и к функционированию как своего рода интенсификаторы (ср. tiefe Unsicherheit, Trauer; schwere Sorgen).

Есть основание полагать, что функция качественно-оценочной характеризации, изначально присущая некоторым рассматриваемым деривационным моделям прилагательных и субстантивным и адъективным 
композитам, может быть нейтрализована в зависимости от иллокутивной направленности высказывания в условиях дискурса за счет возрастающей доминантности интенсифицирующей функции. Анализ иллюстративного материала показывает, что нередко сема оценки реализуется совместно с семой интенсивности, позволяя последней дополнять или усиливать оценочную характеристику объекта или действия. Такие языковые единицы, на наш взгляд, образуют «промежуточные зоны» функционально-семантических полей сравнения, качества, оценки, интенсивности. Однако при коммуникативно обусловленной реализации прагматической целеустановки адресанта интенсифицирующая функция существительного занимает доминирующую позицию, тогда как другие значения качества и оценки утрачивают ведущую роль, так, например композит die Affenhitze / адская жара (модель $\mathrm{S}+\mathrm{S}$ ) определяется в толковом словаpe как sehr große Hitze / очень сильная жара [3] и выступает своего рода интенсификатором в предложении: Es war keine Waldromantik, auf wankenden Plattformen bei Affenhitze stundenlang mit Feldstechern den Horizont abzusuchen / Это была не лесная романтика, на неустойчивых платформах в адскую жсару часами осматривать горизонт из полевого бинокля, где интенсифицирующая функция детерминанта-существительного служит усилителем при выражении отрицательного отношения автора к действию, в данном случае - к скучному занятию часами рассматривать что-то в бинокль, и адская жара только усиливает негативную оценку происходящего, причем качественная характеристика становится неважной, в то время как сохраняют актуальность значения оценочности и интенсивности высказывания.

Аналогичную ситуацию можно наблюдать и в композитах типа A + S. Так, например, композит die Bitterkälte / сильный (дословно - горький) холод является качественно-оценочной характеристикой, что и подчеркивается в предложении: Bitterkälte bei Tag und Minustemperaturen bei Nacht als Prognose für mehr Schneefall [8]. Однако тесная взаимосвязь оценочности и интенсивности позволяет использовать в определенном речевом акте данное существительное как интенсификатор, ср.: Aber mir taten die Fans, die in der so starken Bitterkälte standen, immerleid / Но мне всегда было жаль фанатов, которые стояли на таком сильном холоде [9].

Интенсифицирующая функция может стать основной в речевом акте и у сложных прилагательных, прежде всего прилагательных со значением более интенсивного проявления признака с категориальным значением сравнения, таким как hauchzart (модель $\mathrm{S}+\mathrm{A})$ - ganz besonders zart, zart wie Hauch [3], coдержащего значение усиления признака изначально. Однако при конвенционально закрепленном за пер- вым компонентом оценочно-интенсифицирующим значении оно может быть доминирующим в определенном дискурсе, например: Die deutsche Wirtschaft dürfte im Sommer hauchzart an einer Rezession vorbeigeschrammt sein / Рецеессия слегка затронет экономику этим летом [4], где автор не просто дает оценку состояния немецкой экономики, но при помощи интенсификатора-прилагательного подчеркивает необходимость относиться к происходящему предельно осторожно.

Что касается прилагательных типа hochpathetisch (модель A + A), то они содержат сему интенсивности изначально и могут быть проинтерпретированы с помощью наречия sehr-очень. При этом в контексте данная сема может быть реализована как самостоятельно, например: Er las 1952 in Niendorf hochpathetisch / Он читал в 1952 г. в Ниндорфе слишком пафосно [4], так и с помощью дополнительных интенсификаторов: Das ist hochpathetisch und kitschig und märchenhaft / Это слишком пафосно, вычурно, феерично [4]. В данном речевом акте сема интенсификации в композите-прилагательном уточняется аккумуляцией других лексических единиц (в данном случае - других прилагательных), поддерживающих идею «особенности» объекта или действия, что, кстати, выражается и за счет повтора союза. При использовании сложных прилагательных модели $\mathrm{A}+\mathrm{A}$, которые содержат сему интенсивности, это можно интерпретировать с помощью наречия sehr, а также других дополнительных наречий-интенсификаторов или усилительной частицы zи. Данную особенность можно объяснить повышенной частотностью употребления наречия sehr, а соответственно некоторой «стертостью» его значения усиления для выражения определенных функций, таких как оценка, интенсивность, экспрессивность.

\section{Выводы}

Как вытекает из вышеизложенного, одной из возможностей реализации прагматического потенциала рассмотренных выше языковых единиц - конституентов функционально-семантических полей сравнения, качества, оценки, интенсивности - является их способность «переключаться» на выполнение семантических функций, свойственных конституентам, соположенных полей, в частности, на выполнение интенсифицирующей функции. Подобный функционально-семантический сдвиг, обусловленный в исторически длительной перспективе высокой частотностью их использования в дискурсивном пространстве, может в итоге приобретать системообразующий характер, как это имеет место в случае с КФЕ и определенными деривационными и композитными моделями. 
Но в принципе, как свидетельствует анализ иллюстративного материала, такая перестройка - процесс речетворческий и характеризует прежде всего единицы периферийных сегментов. Обладая некомплектностью семного состава плана содержания по отношению к категориальному значению ядерных конституентов, они открыты для выполнения несвойственных им функций в зависимости от контекстуального окружения, и в первую очередь от ситуации общения. Тем самым создаются предпосылки для образования промежуточных зон между соположенными ФСП, куда входят упомянутые выше периферийные конституенты.

Рассмотренный процесс функционально-семантической перестройки на выполнение конституентами функционально-семантических полей сравнения, качества, оценки, интенсивности является частным случаем бифункциональности языковых единиц, наглядно демонстрирующим динамику развития функционально-семантических полей и континуальность языковой системы в целом.

\section{ЛИТЕРАТУРА}

1. Щерба Л. В. Избранные труды по языкознанию и фонетике. Т. 1. Л. : ЛГУ, 1958. 182 с.

2. Remarque E.-M. Im Westen nichts neues. Moskau : Jupiter-Inter, 2004. $213 \mathrm{~S}$.

3. Duden-online. Wörterbuch der deutschen Sprache. URL: https://www.duden.de

4. Digitales Wörterbuch der deutschen Sprache. URL: https://www.dwds.de/

5. Безрукова В. В. Интенсификация и интенсификаторы в языке и речи (на материале английского языка) : дис. ... канд. филол. наук. Воронеж, 2004. 222 с.

6. Friedrich $W$. Moderne deutsche Idiomatik : Systematisches Wörterbuch mit Definitionen und Beispielen. München, 1976. 824 S.

Нацииональный исследовательский Нижегородский государственный университет имени Н. И. Лобачевского

Постникова С. В., профессор кафедры зарубежной лингвистики Института филологии и журналистики

E-mail: postnikova@flf.unn.ru

Егорова В. Н., преподаватель кафедры зарубежной лингвистики Института филологии и журналистики

E-mail: egorova@flf.unn.ru

Ефимов А. А., преподаватель кафедры зарубежной лингвистики Института филологии и журналистики

E-mail: efimov@flf.unn.ru

Поступила в редакцию 1 марта 2021 г.

Принята к публикаџии 15 июня 20212.
7. Постникова С. В. Разряды прилагательных в современном немецком языке : дис. ... д-ра филол. наук. Н. Новгород, 1992. 441 с.

8. Nach Welt. URL: https://www.nach-welt.com/bitterkalte-bei-tag-und-minustemperaturen-bei-nacht-als-prognose-fur-mehr-schneefall/

9. Электронный корпус немецкого языка. URL: https://cosmas2.ids-mannheim.de/cosmas2-web/

\section{REFERENCES}

1. SHHerba L.V. Izbrannye trudy po yazykoznaniyu $i$ fonetike [Selected works on linguistics and phonetics]. T. 1. L.: LGU, 1958. 182 p.

2. Remarque E.-M. Im Westen nichts neues. Moscow: Jupiter-Inter, 2004. 213 p.

3. Duden-online. Wörterbuch der deutschen Sprache. Available at: https://www.duden.de

4. Digitales Wörterbuch der deutschen Sprache. Available at: https://www.dwds.de/

5. Bezrukova V. V. Intensifikatsiya i intensifikatory $v$ yazyke i rechi (na materiale anglijskogo yazyka) [Intensification and intensifiers in language and speech (based on the material of the English language)]. Dis. ... kand. filol. nauk. Voronezh, 2004. 222 p.

6. Friedrich W. Moderne deutsche Idiomatik: Systematisches Wörterbuch mit Definitionen und Beispielen. München, 1976. $824 \mathrm{p}$.

7. Postnikova S. V. Razryady prilagatel'nykh v sovremennom nemetskom yazyke [Categories of adjectives in modern German]. Dis. ... d. filol. nauk. N. Novgorod, 1992. $441 \mathrm{p}$.

8. Nach Welt. Available at: https://www.nach-welt.com/ bitterkalte-bei-tag-und-minustemperaturen-bei-nacht-alsprognose-fur-mehr-schneefall/

9. EHlektronnyj korpus nemetskogo yazyka [Electronic corpus of the German language]. Available at: https://cosmas2.ids-mannheim.de/cosmas2-web/

Lobachevsky National Research Nizhny Novgorod State University

Postnikova S. V., Professor of the Foreign Linguistics Department of Institute of Philology and Journalism

E-mail:postnikova@flf.unn.ru

Egorova V. N., Lecturer of the Foreign Linguistics Department of Institute of Philology and Journalism

E-mail: egorova@flf.unn.ru

Efimov A. A., Lecturer of the Foreign Linguistics Department of Institute of Philology and Journalism

E-mail: efimov@flf.unn.ru

Received 1 March 2021

Accepted 15 June 2021 


\section{Для цитирования:}

Постникова С. В., Егорова В. Н., Ефимов А. А. Бифункциональность как отражение динамики развития языковой системы (на материале современного немецкого языка) // Вестник Воронежского государственного университета. Серия: Лингвистика и межкультурная коммуникация. 2021. № 3. C. 67-72. DOI: https://doi. org/10.17308/lic.2021.3/3582

\section{For citation:}

Postnikova S. V., Egorova V. N., Efimov A. A. Bifunctionality as a reflection of the dynamics of the development of the language system (on the data of modern German). Proceedings of Voronezh State University. Series: Linguistics and Intercultural Communication. 2021. No. 3. Pp. 6772. DOI: https://doi.org/10.17308/lic.2021.3/3582 